\title{
An Immunohistochemical and Quantitative Examination of Dorsal Root Ganglion Neuronal Subpopulations ${ }^{1}$
}

\author{
JACK PRICE ${ }^{2}$ \\ Medical Research Council, Neuroimmunology Projecl, Department of Zoology, University College London, Gower Street, \\ London WC1E 6BT, United Kingdom
}

\begin{abstract}
Sensory neurons of adult rat lumbar dorsal root ganglia were labeled in cryostat sections with antisera against tyrosine hydroxylase (TH), substance P (SP), and somatostatin (SOM), and with a monoclonal antibody (RT97) that labels the 145- and 200-kilodalton (kd) subunits of neurofilaments. These neurons were also histochemically stained for fluoride-resistant acid phosphatase (FRAP), and the size and distribution of each population were determined. In addition, the double-label immunoperoxidase technique of Sternberger and Joseph (Sternberger, L. A., and S. A. Joseph (1979) J. Histochem. Cytochem. 27: 1424-1429) was employed to determine whether these antibodies labeled distinct or overlapping populations of neurons. The results indicate that the dopaminergic $\left(\mathrm{TH}^{+}\right)$cells constitute a separate population from the $\mathrm{SP}^{+}$and $\mathrm{SOM}^{+}$neurons and that the size distributions of the $\mathrm{SP}^{+}, \mathrm{SOM}^{+}, \mathrm{TH}^{+}$, and $\mathrm{FRAP}^{+}$cells are all different despite the fact that all of these subpopulations are part of the "small dark" subpopulation as indicated by their size and by the fact that they are RT97 ${ }^{-}$. RT97 is a putative marker for the "large light" population (Anderton, B., H. B. Coakham, J. A. Garson, A. A. Harper, and S. N. Lawson (1982) J. Physiol. (Lond.) 334: 97-98P). Furthermore, the distribution data indicate that all of the "small dark" cell subpopulations are not evenly distributed within the ganglion, and the staining with RT97 and with another antibody which recognizes the 68-kd neurofilament subunit indicates heterogeneity among the "large light" population. These results are discussed in terms of the significance of the "small dark"-"large light" classification.
\end{abstract}

There is a considerable body of older literature that suggests that the sensory neurons of mammalian dorsal root ganglia (DRG) can be divided into two histological types called "large light" and "small dark" on the basis of their staining properties under the light microscope (Hatai, 1902; Preto Parvis, 1954; Scharf, 1958; Andres, 1961; Lawson et al., 1974). More recent electron microscopic analysis has

Received August 6, 1984; Revised December 10, 1984;

Accepted January 2, 1985

\footnotetext{
'I would like to thank Anne Mudge and Martin Raff for their invaluable advice, support, and encouragement during the period of this work and Richard Hynes for his critical reading of the manuscript. I am grateful to Drs. T. H. Joh, S. E. Leeman, G. Shaw, and J. N. Wood for their kind gifts of antibodies and to the Medical Research Council and the Wellcome Foundation for financial support.

${ }^{2}$ Present address: Center for Cancer Research, Massachusetts Institute of Technology, Cambridge, MA 02139.
}

confirmed the impression of the existence of two basic types of DRG neurons (usually termed types " $\mathrm{A}$ " and " $\mathrm{B}$ " by electron microscopists rather than large light and small dark), and such studies have resulted in the extension of this basic classification (Andres, 1961; Duce and Keen, 1977; Rambourg et al., 1983). As a result, this classification system has achieved widespread acceptance, although it should be borne in mind that it is not the only one to have been proposed (see Lieberman, 1976, for review). More importantly, the functional significance of this histological classification is not known. Various physiological parameters such as conduction velocity, modality, and adaptation rate serve to distinguish a large number of functional types of sensory neurons, but it is not clear how these are related to the two basic histological types.

One reason why the functional classifications have not been mapped onto the histological ones is the absence of histochemical markers which can identify different physiological types. For example, since the neurotransmitters of sensory neurons are not known, antisera against neurotransmitters or their synthesizing enzymes cannot be used in immunohistochemical studies. This situation has recently improved with the demonstration of a number of neuroactive peptides in DRG neuron subpopulations, notably substance $P$ (SP) (Hokfelt et al., 1975a, b, 1976) and somatostatin (SOM) (Hokfelt et al., 1975c). These peptides may or may not be transmitters in the classical sense, but they no doubt play some physiological role and thus can be considered to label a functionally related group of cells. Also, we recently demonstrated that some DRG neurons are dopaminergic and can be identified with an antiserum against tyrosine hydroxylase (TH) (Price and Mudge, 1983). This was the first demonstration of a "classical" neurotransmitter in DRG neurons. As a consequence, with markers likc $\mathrm{TH}, \mathrm{SP}$, and SOM, one is in a position to ask how these subpopulations fit into the "small dark""large light" classification.

The $\mathrm{TH}^{+}, \mathrm{SP}^{+}$, and $\mathrm{SOM}^{+}$subpopulations are all predominantly small cells, and it might be assumed that they belong to the "small dark" catcgory. However, sizc alone is not a reliable criterion for classification as the "large light" population has a very broad size range and overlaps with the small dark size range (Lawson et al., 1974). Also, some of the cells containing SP and SOM seem to fall into the area of overlap.

The prosent study addresses two questions. First, are the dopaminergic neurons a distinct subpopulation from the peptide-containing neurons already described, or do they constitute a subpopulation of one of these populations? It is known from previous studies that SP-containing and SOM-containing sensory neurons are nonoverlapping subpopulations (Hokfelt et al., 1976) and that neither of these overlap with the subpopulation of cells that contain fluoride-resistant acid phosphatase (FRAP) (Knyihar, 1971; Nagy and Hunt, 1982), one of a number of distinctive phosphatases found in DRG neurons. Here, I use a double-staining immunoperoxidase technique to show that the dopaminergic ncurons do not contain either SP or SOM.

The second question is whether the dopaminergic, SP, and SOM 
and FRAP subpopulations of sensory neurons all fall within the "small dark" population or whether they include cells that are in the "large light" category. This was investigated in two ways. First, the four subpopulations were sized. Second, their neurofilament content was analyzed using a monoclonal antibody, RT97, which reacts with the heaviest two neurofilament subunits (Wood and Anderton, 1981). This antibody has been reported to label exclusively the large light cells in these ganglia (Anderton et al., 1982). The results indicate that the $\mathrm{TH}^{+}, \mathrm{SP}^{+}$, and $\mathrm{SOM}^{+}$subpopulations all fall within the small dark population. The data also show, however, that each of these subpopulations has a distinctly different size range, indicating a substantial nonequivalence between the subpopulations of the small dark sensory neurons. In addition, data are presented which suggest that all small dark subpopulations may not be evenly distributed within the ganglion.

\section{Materials and Methods}

Antisera. The following primary antisera were used in this study: rabbit anti-TH, produced and characterized by Joh et al. (1973) and used diluted 1:1000; rabbit anti-SP, the Rd2 antiserum described by Barber et al. (1979) and used diluted 1:1000; rabbit anti-SOM from RIA (Sunderland, Inited Kingdom), used 1:200; RT97, a mouse monoclonal antibody produced and characterized by Wood and Anderton (1981), which reacts with the 200-and 145-kilodalton (kd) neurofilament subunits; ascites fluid used diluted 1:200; and rabbit anti-68k, an antiserum produced by Shaw and Weber (1981) which recognizes the 68-kd subunit of neurofilaments, used diluted 1:100. In control experiments, the anti-SP and anti-SOM were adsorbed, each with the appropriate peptide, and were used at similar dilutions. The other rabbit antisera were replaced in control experiments with normal rabbit serum (NRS) at a similar dilution, and the RT97 was replaced with a normal mouse serum at a similar dilution.

Tissue preparation. Adult Sprague-Dawley rats were perfused intracardially with $0.9 \%$ saline followed by freshly prepared $4 \%$ paraformaldehyde (PFA) in phosphate-buffered saline (PBS), pH 7.2. DRG from levels $L 5$ and $L 6$ were removed and fixed overnight by immersion in 4\% PFA. After $2 \mathrm{hr}$ in 30\% sucrose in PBS $+0.1 \%$ sodium azide, the ganglia were mounted in OCT embedding medium (Tissue Tec, Miles Scientific, Naperville, IL) and frozen in isopentane, cooled to freezing in liquid nitrogen. Frozen sections were then cut at $10 \mu \mathrm{m}$ on a Bright cryostat, collected onto gelatinized glass slides, and stored at $-20^{\circ} \mathrm{C}$. In experiments using anti-peptide sera, $6 \mathrm{hr}$ before perfusion the animal received a single subcutaneous injection of colchicine (Sigma Chemical Co., St. Louis, MO), $20 \mathrm{mg} / \mathrm{ml}$, locally to the lumbar region. This was done under ether anesthesia.

In some experiments, the distribution of different cell types within a DRG was studied. After perfusion, the lumbar spinal cord and DRG were exposed from the dorsal aspect. The spinal cord was then carefully removed, avoiding any disturbance of the DRG. The L6 DRG were then marked on their medial aspect by stitching a fine loop of thread into the capsule wall on that side of the ganglion. Similarly, a loop of thread was placed around the rootlets at the rostral end of each ganglion. Both L6 ganglia were marked in this fashion, enabling the ganglia to be subsequently mounted in any desired orientation. Twn orientations were used. In some cases the pair of ganglia was mounted longitudinally with both rostral ends pointing in the same direction and both with their lateral aspects outward. Hence, during sectioning, the ganglia were being cut from the dorsal through to the ventral surface. In other cases, the ganglia were also cut longitudinally, but from the medial through to the lateral surface.

Peroxidase immunohislochemistry. Single-dnligen in murnoperoxidase staining using the RT97 antibody was performed as follows. The sections were first incubated in $0.5 \%$ Triton X-100 in PBS for $15 \mathrm{~min}$. This was necessary for adequate accessibility of antibody to antigen. The endogenous peroxidase was then blocked with $0.3 \%$ hydrogen peroxide in water, and the sections were incubated overnight at $4^{\circ} \mathrm{C}$ in RT97 diluted in PBS with $4 \%$ calf serum and $0.1 \%$ Triton $X-100$. (Unless specified otherwise, all antibody dilutions and washings were performed in the above buffer.) The sections were then washed twice for $10 \mathrm{~min}$ and then incubated for $1 \mathrm{hr}$ in peroxidase-conjugated goat anti-mouse immunoglobulin (GaMlg-P: Tago Inc., Burlingame, CA), used 1:100. Following a further wash, the sections were reacted with a solution of $3,3^{\prime}$-diaminodenzidine tetrahydrochloride (DAB; $0.5 \mathrm{mg} \cdot \mathrm{ml}^{-1}$, Polysciences, Northampton, United Kingdom) and hydrogen peroxide $(0.06 \%)$ in Tris- $\mathrm{HCl}$ buffer $(50 \mathrm{~mm}, \mathrm{pH} 7.2)$ for 3 to 5 min. They were then washed twice for $10 \mathrm{~min}$ in distilled water, mounted in glycerol, and viewed with a Zeiss microscope fitted with Nomarski optics.
For double-antigen immunoperoxidase staining, the peroxidase-antiperoxidase (PAP) method of Sternberger and Joseph (1979) was adopted. After a hydrogen peroxidase block, the sections were incubated with a primary antiserum as described for RT97 above. After an overnight incubation, the sections were washed twice for $10 \mathrm{~min}$, incubated for $2 \mathrm{hr}$ at room temperature in sheep anti-rabbit immunoglobulin (ShaRlg; Miles-Yeda Ltd., Rehovot, Israel) diluted 1:50, washed again, and incubated for $2 \mathrm{hr}$ at room temperature with rabbit PAP reagent (Dako-immunoglobulins, Copenhagen, Denmark), diluted 1:100. The sections were then washed twice for $10 \mathrm{~min}$ in Tris buffer ( $50 \mathrm{~mm}, \mathrm{pH} 7.2$ ). The peroxidase was then reacted with DAB and hydrogen peroxide as described above. The reaction was stopped by immersion in Tris buffer. In this manner, the first primary antiserum was visualized with the brown reaction product of $\mathrm{DAB}$. After a briet wash in water, the same sections were reincubated overnight at $4^{\circ} \mathrm{C}$ with a second rabbit antiserum. They were then reprocessed according to the same PAP procedure just described except that, this time, the peroxidase was reacted with 4-chloro1-naphthol (4CN; $0.5 \mathrm{mg} \cdot \mathrm{ml}^{-1}$, Sigma) for 10 to $15 \mathrm{~min}$ to give a blue reaction product. The sections were then finally washed in water, mounted in glycerol, and viewed under Nomarski optics.

When the second antibody in the double-staining procedure was RT97, the PAP methodology in the sccond step was replaced with a procedure appropriate to the mouse antibody that was described above except that being the second peroxidase reaction, $4 \mathrm{CN}$ was used as the peroxidase reagent.

In control experiments, either the anti-TH serum was replaced with a similar dilution of NRS, or the anti-peptide serum was adsorbed with either SP or SOM, as appropriate. In both cases, the staining specific to the omitted antiserum disappeared. In double-negative controls, no staining was seen.

There are a number of potential problems with this double-staining technique against which one has to control. These were discussed at length by Sternberger and Joseph (1979), and I have previously addressed the subject in the context of the types of experiment described here (Price, 1984). Briefly, there are two potential hazards. One is that of cross-reactivity between reagents involved in the two different PAP steps. This does not happen, as can be seen from the data presented here, where one can see blue and brown cells and no cross-reactivity. The second problem is whether one can identify double-stained (i.e., blue and brown) cells. Such a result is not shown here, but I have previously demonstrated that double stanıng is resolvable as long as the intensities of both the blue and the brown reactions are kept low. Such conditions were maintained throughout this study.

Fluorescent immunohistochemistry. DRG sections prepared as above were incubated overnight in RT97 diluted in PBS $+4 \%$ calf serum (CS) + $0.1 \%$ Triton $X-100$. The sections were then washed for $10 \mathrm{~min}$ and then incubated for $45 \mathrm{~min}$ with rhodamine-conjugated goat anti-mouse immunoglobulin (Rd-GaMlg; Cappel Laboratories, Cochranville, PA) diluted 1:100. After a further wash for $10 \mathrm{~min}$, the sections werc incubated for $2 \mathrm{hr}$ with an affinity-purified rabbit anti-68k serum (Shaw and Weber, 1981) diluted in the same buffer as above. The sections were again washed and then incubated for 45 min with lluorescein-conjugated goat anti-rabbit immunoglobulin (FFGaRlg; Cappel) diluted 1:100. After a final 10-min wash, the sections were mounted in glycerol and viewed with a Zeiss epifluorescent microscope.

Both the Rd-GaMIG and the Fl-GaRlg sera had previously been adsorbed with Sepharose-coupled immunoglobulin from either mouse or rabbit, as appropriate, to remove cross-reacting antibodies. Control experiments were also run in which one of the two primary antisera was replaced with NRS at a similar dilution. No inappropriate cross-reactivity was observed.

FRAP histochemistry. This was done according to the method of Gomori as described by Nagy and Hunt (1982). After washing in acetate buffer (25 $\mathrm{mM}, \mathrm{pH} 5.0$ ), sections were incubated for $2 \mathrm{hr}$ in acetate buffer containing $10 \mathrm{~mm}$ sodium $\beta$-glycerophosphate, $3.5 \mathrm{~mm}$ lead nitrate, and $0.3 \mathrm{~mm}$ sodium fluoride. Following another 30 -min wash in acetate buffer, the reaction product was visualized by incubating the sections for $10 \mathrm{~min}$ in $0.2 \mathrm{M}$ acetic acid containing $90 \mathrm{~mm}$ sodium sulfite. Following extensive washes in water, the sections were finally mounted in glycerol.

Cell sizing. For cell sizing, the entire ganglion was sectioned longitudinally, and alternate sections were stained with different subpopulation markers. In this way, cells from all areas of the ganglion were included and the effects of random variations in colchicine application of fixation between preparations had a minimal influence on the outcome of the experiments. Cells were sized by measuring two diameters (perpendicular to each other) of a stained cell, using an eyepiece graticule with a microscope fitted with Nomarski optics. The mean of these two measurements was taken to give the average cell diameter. Only cells in which the nucleolus was apparent were sized. Total population sizing was done on seclions from the same series that had been stained with Giemsa stain in order to visualize all neuronal cell bodies. The 
number of cells counted was between 200 and 250 for SP, SOM, and FRAP subpopulations, and 84 for the $\mathrm{TH}^{+}$subpopulation. The number of Giemsastained cells counted was 842 . In each case, sections from at least three animals are included in the counts. In the case of $\mathrm{TH}$, counts came from sections from eight different experiments. All of the experiments were done on ganglion L6 except those using the anti-TH serum, which included data from $L 5$ and $L 6$.

\section{Results}

Double staining - TH and pcptides. Figure 1, $a$ and $b$, shows the results of double-staining PAP experiments with $\mathrm{TH}-\mathrm{SOM}$ and $\mathrm{TH}$ $\mathrm{SP}$, respectively. In both cases, one sees cells stained with anti-TH and others stained with the anti-peptide quite clearly, but in no case were cells seen that contained both TH and peptide. This result was observed which ever primary antiserum was applied first and hence stained brown. In all cases, the majority of cells in the ganglion were unstained with either antiserum.

Subpopulation sizing. Figure 2 shows the size distribution of the total neuronal population of L6 DRG. It has a roughly bimodal form, and it is known from the work of a number of previous workers (see Lawson, 1979) that there is a small cell population with a size range from about 15 to $35 \mu \mathrm{m}$ in diameter and with a modal value of about $25 \mu \mathrm{m}$. Although it is not clear from these data, Lawson (1979) has shown that the "large light" population, which includes essentially all of the cells above $35 \mu \mathrm{m}$ in diameter, overlaps the small cell population considerably and so includes a number of the cells below $35 \mu \mathrm{m}$ in diameter, even to the extent of including some of the smallest neurons in the ganglion. (Note that, for clarity, the graph shown in Fig. 2 has been arbitrarily truncated at $50 \mu \mathrm{m}$. Cells up to a diameter of $70 \mu \mathrm{m}$ were actually measured, although only a few cells fall in this higher range.)

Figure 3 shows the size distribution of the TH, SP, SOM, and FRAP subpopulations. (Note that the graph represents the percentage of cells within each subpopulation that has a particular cell diameter; it does not reflect the percentage each subpopulation constitutes of the total neuronal population.) It can be seen that all four subpopulations fall within the "small dark" cell size range (15 to $35 \mu \mathrm{m}$ diameter), and yet the sice distributions of the four subpopulations are distinctly different. If compared statistically by either analysis of variance or by nonparametric statistics, all four distributions can be shown to be significantly different. This is not surprising as even the smallest of differences will be statistically significant with such large numbers in each grouping. However, if the populations are qualitatively compared, the following points are revealed.

1. The $\mathrm{TH}^{+}$cells are smaller than the others. Not only is the mode of the $\mathrm{TH}^{+}$cells only 17 to $18 \mu \mathrm{m}$ in diameter but one also finds no $\mathrm{TH}^{+}$cells larger than $24 \mu \mathrm{m}$ in diameter, whereas this is the mode of the "small dark" population. Thus, the $\mathrm{TH}^{+}$population constitutes a group of cells at the small end of the population range.

2. The $\mathrm{SOM}^{+}$cells are considerably larger than any of the other subpopulations. The modal value for $\mathrm{SOM}^{+}$cells is $29 \mu \mathrm{m}$ and there is little overlap between the SOM group and the SP and FRAP group and virtually no overlap between SOM and TH populations. The $\mathrm{SOM}^{+}$cells, then, are the largest cells in the "small dark" range

3. The SP and FRAP distributions are very similar. Their modes differ by less than $2 \mu \mathrm{m}$ (which is approximately the smallest difference that could be observed with the graticule and microscope that were used), and the range of sizes covered by the two populations is almost identical. Both populations are skewed slightly toward the high side. The modes of both subpopulations fall very close to that of the peak one finds in the total population.

Subpopulation distribution. In some experiments pairs of $\mathrm{L} 6$ ganglia were sectioned through from their dorsal to ventral aspects and all of the sections were stained with anti-SP or anti-SOM. This was done to see if there was any evidence for a preferred distribution of either of these subpopulations within the ganglion. The experiments showed that there was some variation in the number of cells that stained with either antiserum. However, this variation did not seem to be systematic and no preferred distribution was noticed.
The result with FRAP was quite different. In the experiments where the ganglia were cut dorsal through to ventral and stained for FRAP the dorsalmost sections contained considerably more RAP $^{+}$cells than the ventralmost. This differenco was quite extreme. In some dorsal sections, 50 to $70 \%$ of the cells were stained, whereas some ventral sections had only one or two FRAP $^{+}$cells in the whole section. To confirm this finding, some sections were cut through ganglia turned by $90^{\circ}$ from the dorsal through ventral orientation described above. These ganglia were cut medial through to latcral. The prediction would be in this experiment that one would generate the situation in which the $\mathrm{FRAP}^{+}$cells were found predominantly in one half of a section. Such a section is shown in Figure $4 a$. In this section, dorsal is to the right and rostral is downwards. One can see that there are a number of heavily stained cells (a higher power example of which is shown in Fig. 4b) and that these are predominantly located in the dorsal half of the ganglion (the left half of Fig. 4a)

A complication arose, however, when sections of various thick. nesses were stained. The experiments described above were done with 10- $\mu \mathrm{m}$ frozen sections. In some experiments, $20-\mu \mathrm{m}$ sections were taken from various regions within the same series as the 10$\mu \mathrm{m}$ sections. It was clear that in these thicker sections there were far more FRAP ${ }^{+}$cells than in the adjacent $10-\mu \mathrm{m}$ sections. This was most noticeable in the ventralmost sections of the dorsal through to ventral series. In the $10-\mu \mathrm{m}$ sections from this area there were very few FRAP $^{+}$cells, as described above. In the $20-\mu \mathrm{m}$ sections, however, there were essentially as many FRAP $^{+}$cells as in the 10$\mu \mathrm{m}$ dorsalmost sections. In other words, cells were staining for FRAP in 20- $\mu \mathrm{m}$ sections that would be FRAP ${ }^{-}$in $10-\mu \mathrm{m}$ sections.

RT97 immunohistochemistry. Figure 5 shows DRG sections stained with RT97. A subpopulation of cells was stained with this antibody and the cells that were stained were generally large cells. This is in agreement with the observation of Anderton et al (1982). However, the following points were also clear.

1. Not all large cells (greater than $35 \mu \mathrm{m}$ in diameter) were stained (see arrowed cell in Fig. 5a).

2. The range of sizes of cells stained was large: one could find cells of all sizes that were stained, including some of the smallest cells in the ganglion $(\sim 20 \mu \mathrm{m}$ diameter).

3. The pattern and intensity of staining varied considerably. Some cells were heavily stained and seemed to be packed full of neurofilaments. Other colls were much more lightly stained, often in a fine reticular pattern in which the neurofilament appeared as a halo around the nucleus (see arrowed cell in Fig. 5b).

4. The various intensities and patterns of staining did not seem to correlate with size. One could find cells of all sizes with any pattern and intensity of staining.

RT97 double staining with TH, SP, and SOM. The results of these experiments are shown in Figure 1, $c$ to $e$. What these results demonstrated was that $\mathrm{RT} 7^{+}$cells do not contain $\mathrm{TH}, \mathrm{SP}$, or SOM. This is despite the fact that there is considerable overlap in the sizes of the cell stained with the RT97 and the peptide antisera, particularly anti-SOM (Fig. 1C). In these experiments the variety of patterns of neurofilament staining is not as obvious as in those where RT97 was used alone because the animals were treated with colchicine in order to enhance the peptide staining.

A question arises as to whether the cells that do not stain with RT97 have no neurofilaments at all or just lack the heavier two subunits that are recognized by the monoclonal antibody. To address this question, DRG sections were double stained with RT97 and a rabbit antiserum that specifically recognized the smallest neurofilament subunit (anti-68k). As far as could be resolved by this experiment, all of the cells that were RT97 ${ }^{+}$were also anti-68k+, although the intensity of the staining with the two antibodies was not the same: axons were in general very much more strongly labeled by RT 97 than by anti-68k, whereas cell bodies that were stained with both antibodies were much more intensely stained with anti-68k than with RT97. Similarly, the majority of the small cells that 

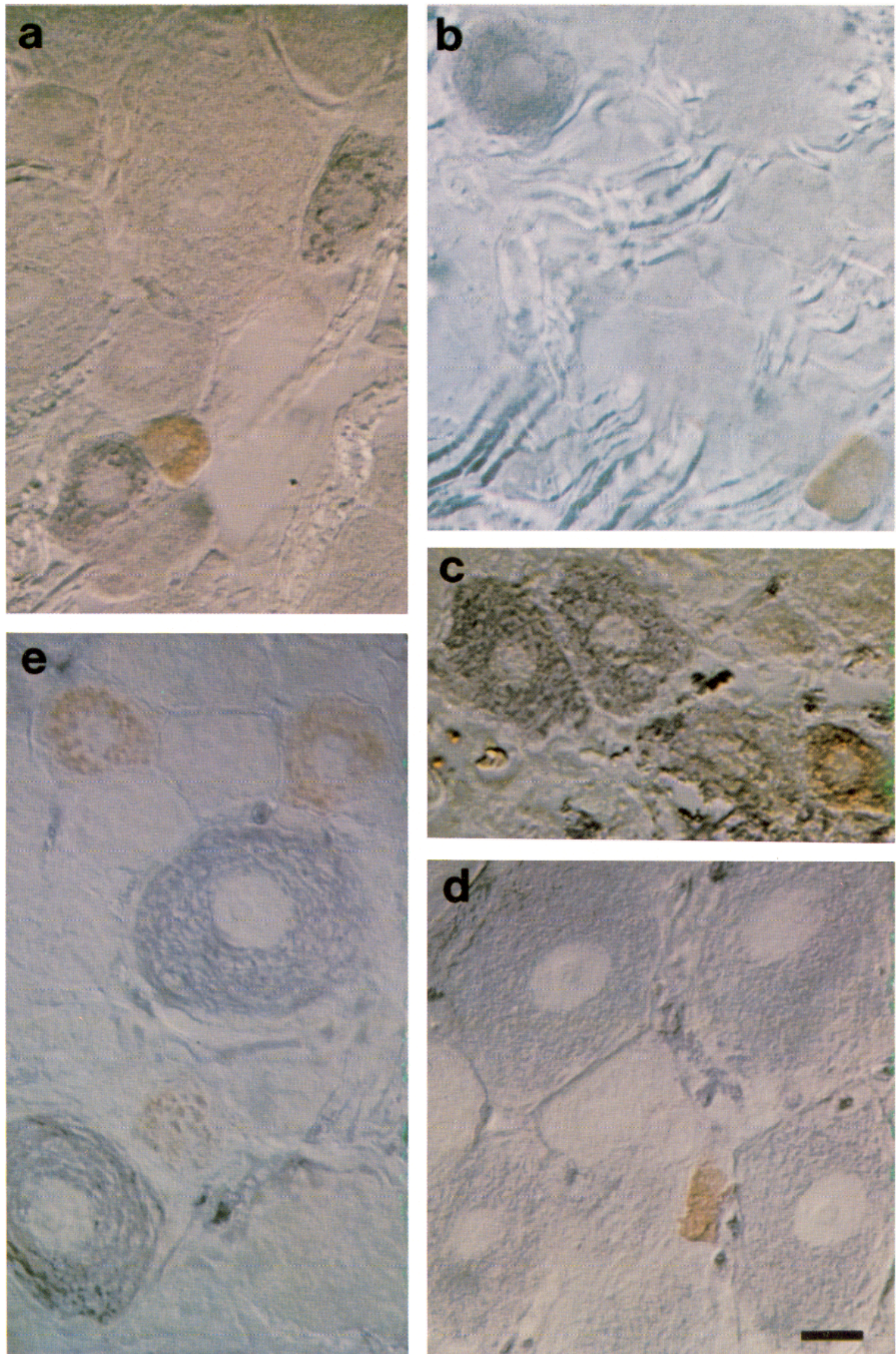

Figure 1. Light micrographs of 10- $\mu \mathrm{m}$ frozen sections of adult rat L5 or L6 DRG, stained using the double-staining PAP technique. a, TH-SOM. One cell is stained for TH in brown and two cells are $\mathrm{SOM}^{+}$in blue. $b, \mathrm{TH}-\mathrm{SP}$. There is one brown $\mathrm{TH}^{+}$and one blue $\mathrm{SP}^{+}$cell. $c$, SP-RT97. The brown cell is SP+ and there are two blue RT97 ${ }^{+}$cells. $d$, TH-RT97. There are a number of large blue RT97 ${ }^{+}$cells and one $\mathrm{TH}^{+}$cell in brown. e, SOM-RT97. SOM ${ }^{+}$cells are stained brown and RT97 ${ }^{+}$cells are stained blue. Scale bar, $20 \mu \mathrm{m}$. 


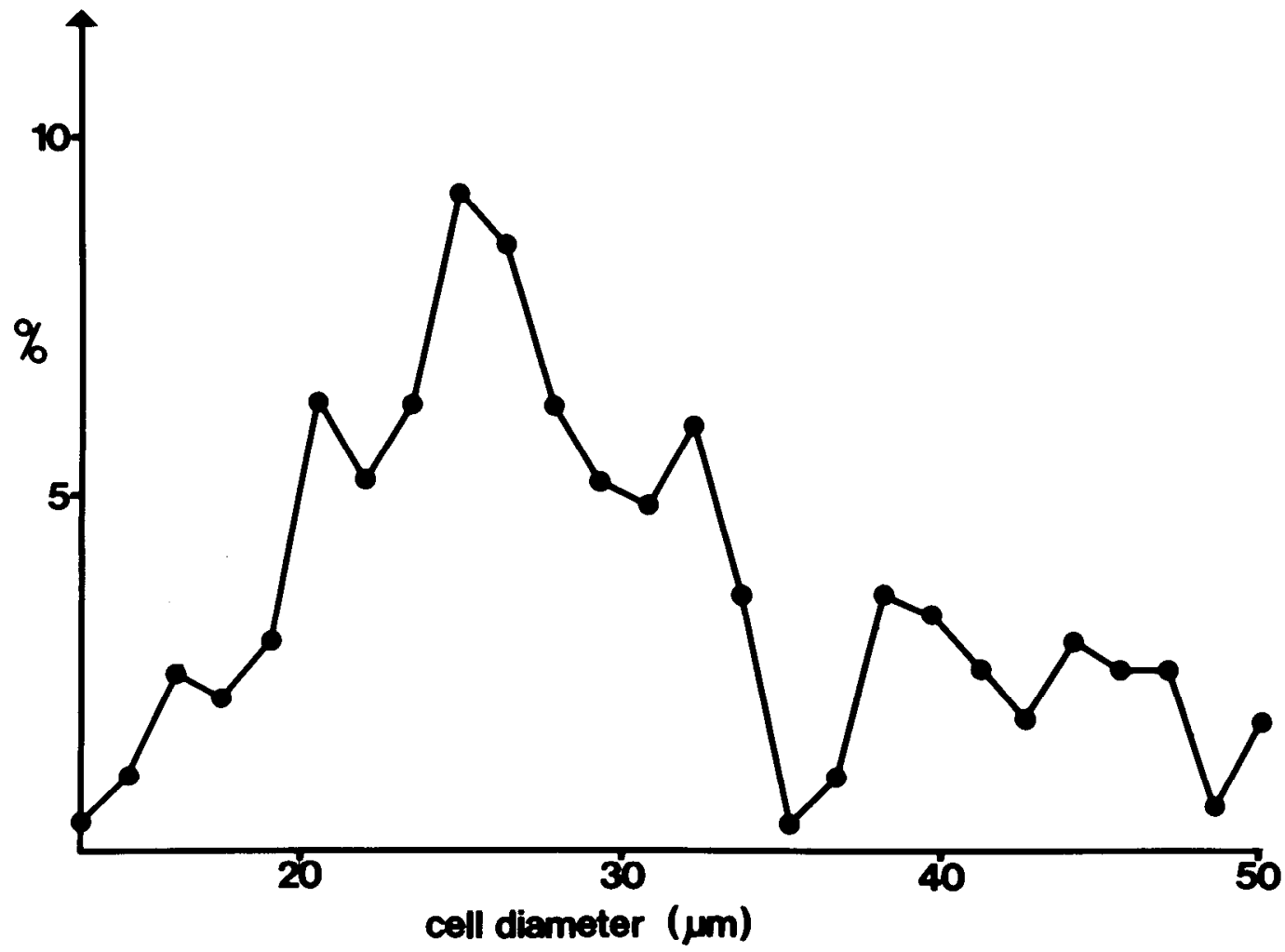

Figure 2. Size distribution of the L6 DRG neuronal population. Abscissa, mean somal diameter of the neurons; ordinate, the number of cells of particular diameter expressed as the percentage of the total number of sized cells.

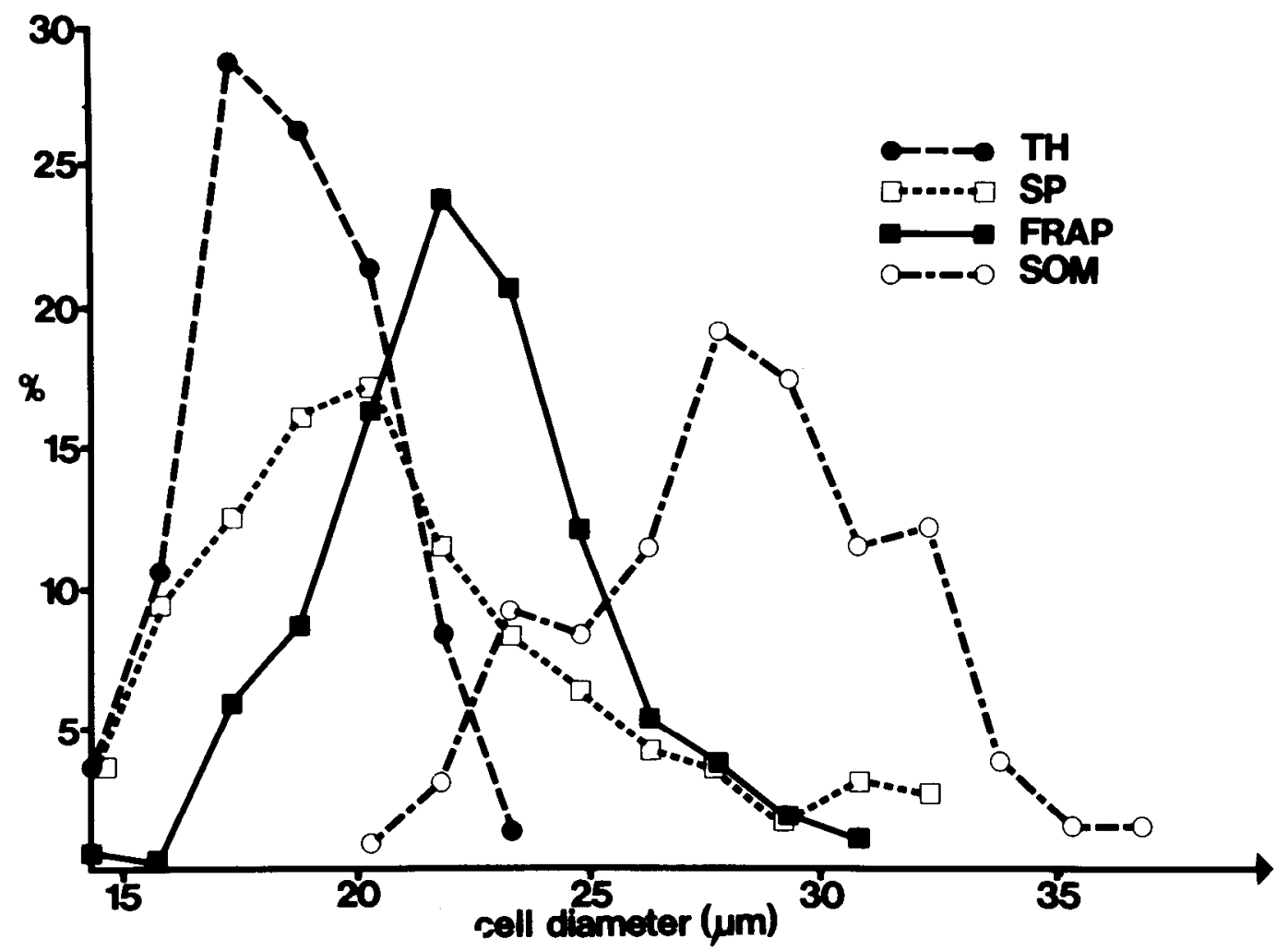

Figure 3. Graph of size distribution of four DRG neuronal subpopulations, i.e., $\mathrm{TH}^{+}, \mathrm{SP}^{+}, \mathrm{SOM}^{+}$, and $\mathrm{FRAP}^{+}$. Abscissa, mean cell diameter; ordinate, number of cells in a subpopulation with a particular diameter, expressed as a percentage of the total number of sized cells in that subpopulation. 


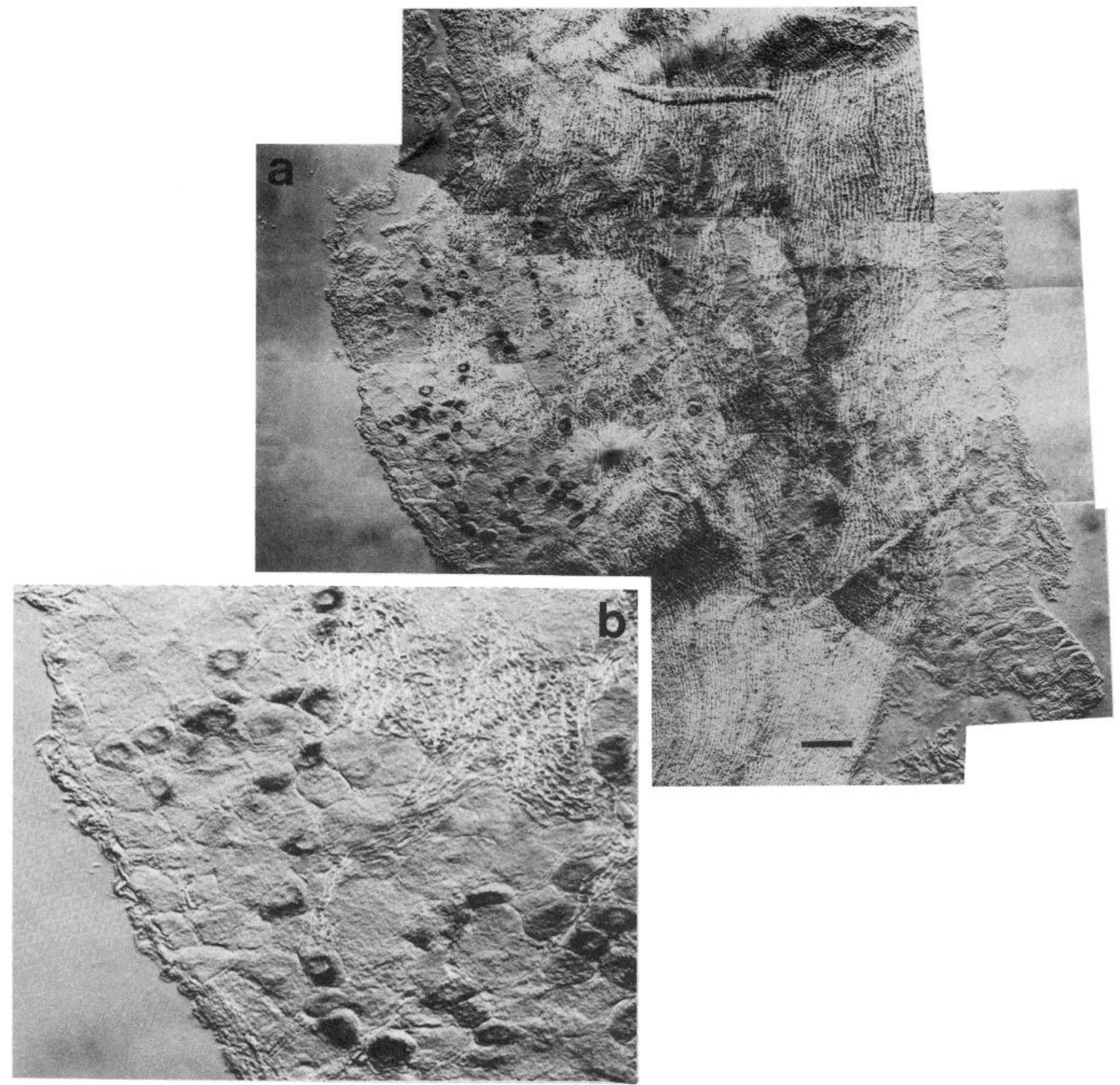

Figure 4. Distribution of FRAP ${ }^{+}$cells. a, Photomontage showing a section from an L6 adult rat DRG. The section has been stained for FRAP and has been orientated such that the dorsal aspect of the ganglion is to the left and the rostral end of the ganglion is directed downward. The figure shows a considerable number of darkly stained cells in the dorsal (left) half of the section but no such FRAP ${ }^{+}$cells in the ventral (right) half. Scale bar, $50 \mu \mathrm{m}$. $b$, An area from the dorsal half of the section, shown in higher magnification.

did not stain with RT97 also failed to stain with the anti-68k serum. However, there was a population of cells which were RT97 ${ }^{-}$and anti- $68 \mathrm{k}^{+}$(Fig. 6). Some of these were quite large cells but some were small cells, well within the "small dark" size range. Thus, it seems likely that some small dark cells have the 68-kd neurofilament subunit although the majority do not. Whether these small $68 \mathrm{k}^{+}$cells correspond to any of the other small dark subpopulations has not been determined in this study.

\section{Discussion}

The double-staining experiments presented in this study show that the $\mathrm{TH}^{+}$neurons of the rat DRG do not contain SP or SOM. Thus, the dopaminergic subpopulation is a separate group of cells from these other subpopulations. Also, the $\mathrm{TH}^{+}$cells have a significantly smaller average diameter than the SP-, SOM-, or FRAP. containing subpopulations. For technical reasons I could not use the double-staining techniques to determine whether the $\mathrm{TH}^{+}$cells contain FRAP. However, when serial sections were stained for either TH or FRAP (data not shown), it was clear that the majority, if not all, of the $\mathrm{TH}^{+}$cells did not contain FRAP.

How do the subpopulations that have been defined histochemically relate to the "small dark" and "large light" populations that have been defined histologically? My data suggest that the $\mathrm{TH}^{+}, \mathrm{SOM}^{+}$, $\mathrm{SP}^{+}$, and $\mathrm{FRAP}^{+}$subpopulations are all subgroups of the small dark population. This conclusion is based on two observations. (1) The size ranges of the four subpopulations all fall between 15 and 35 $\mu \mathrm{m}$ in diameter, which represents the size range of the small dark population. (2) None of the cells in the subpopulations analyzed reacted with the RT97 antibody, which has been suggested to be a 

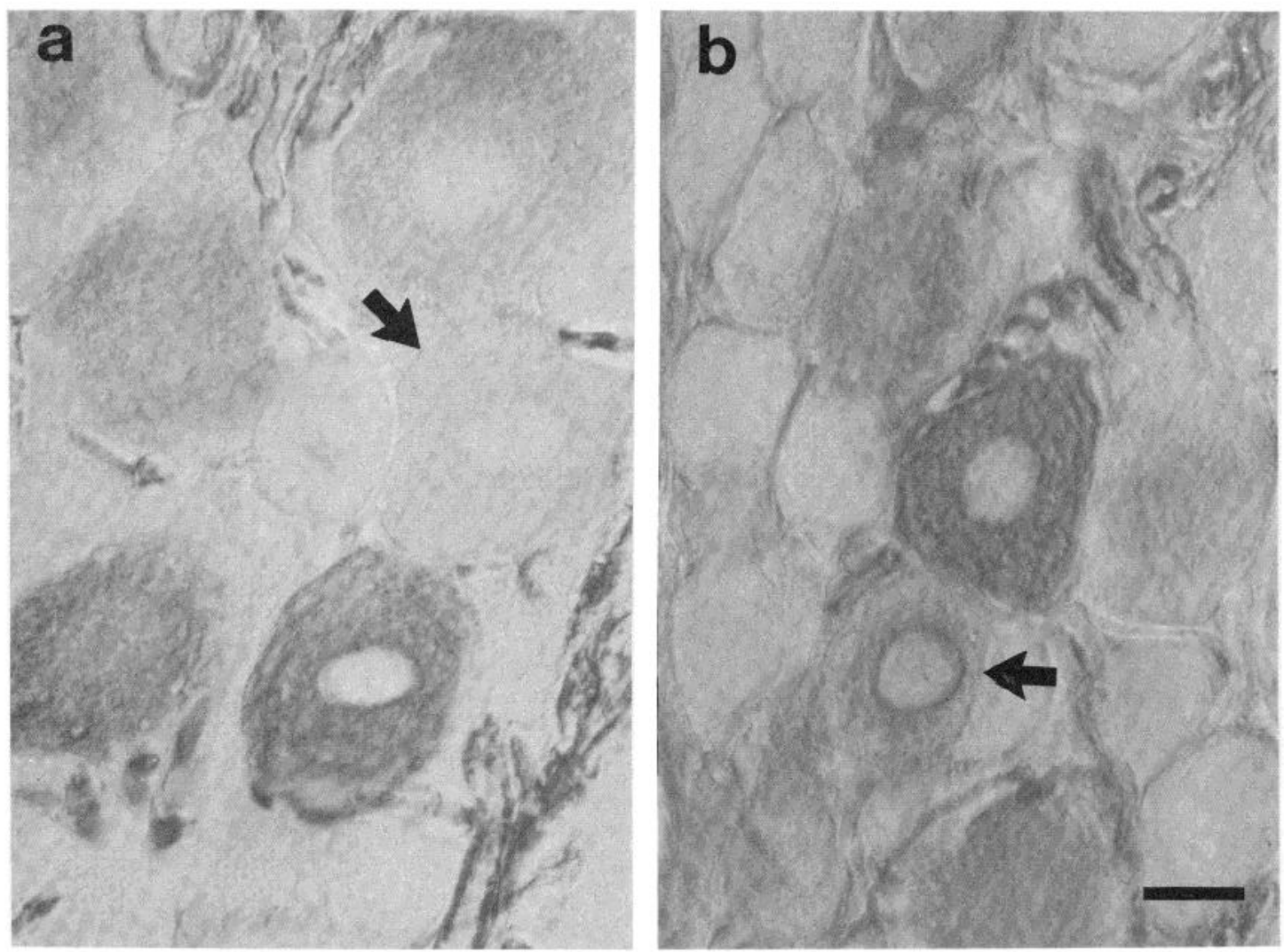

Figure 5. Light micrographs of adult L6 DRG sections stained with RT97. Each photograph shows a number of both stained and unstained neurons. Note also that myelinated axons are stained. The cell indicated by the arrow in a is a large (greater than 35- $\mu \mathrm{m}$ diameter) unstained neuron. The cell indicated by the arrow in $b$ is an example of the perinuclear staining described in the text. Scale bar, $20 \mu \mathrm{m}$.

marker of large light cells (Anderton et al., 1982). (This may or may not be true of the FRAP ${ }^{+}$cells. It was not determined in this study.)

My data also show, however, that the subpopulations that go to make up the "small dark" population are heterogeneous with regard to size. Therefore, although the "small dark" population appears as a single, normally distributed population in the graph in Figure 2, it is actually made up of a number of separate populations with overlapping (but distinct) size distributions.

What about the "large light" population? The RT97 staining confirms what was already known, namely, that the term "large light" is something of a misnomer as these cells have a size range almost as broad as the total population size range (Anderton et al., 1982). The RT97 antibody also indicated a heterogeneity among the "large light" cells. Cells from this population could be either unstained, weakly stained, or very heavily stained with this antibody. It is probable that the heterogeneity of large light neurons revealed by the RT97 staining corresponds to the subclassification of this group of cells by previous authors (Andres, 1961; Jacobs et al., 1975; Duce and Keen, 1977; Rambourg et al., 1983). These classifications were based on the arrangement of subcellular organelles, particularly Nissl bodies, Golgi cells, and mitochondria as demonstrated by electron microscopy, but differences in the arrangement of neurofilaments were also noted. It is not easy, however, to decide which subclass (as defined by any of these previous authors) corresponds with which RT97 staining pattern as described here. In addition, I have not presented any data correlating intensity and pattern of RT97 staining with cell size. This is because classifying the cells in terms of RT97 staining proved to be difficult, and clearly all intensities of staining could exist in cells of all sizes.

It was surprising to find that the anti-68k serum did not stain the same population of cells as the RT97 antibody, because Sharp et al. (1982) had already shown that rat DRG neurons either had all three neurofilament subunits or none at all. This apparent contradic- tion might be explained by the fact that their study was done on young cultures from newborn rats. Whatever the implications of this result for neurofilament heterogeneity, it clearly shows that, although the majority of "small dark" neurons do not have neurofilaments and none have the 145- and 200-kd subunits, some do have filaments of 68-kd subunits. In addition, the "large light" neurons that have little or no RT97 immunoreactivity do have neurofilaments of 68 -kd subunits. By and large, though, it is difficult to know how to consider the RT97- anti-68K ${ }^{+}$cells in relation to the large light-small dark classification without more information about this subpopulation of cells.

The data presented here add weight to the idea that the "small dark"-"large light" classification is a functionally relevant one. It is not clear why the many physiologically different types of sensory neuron should split into two distinct histological types, especially as the distinction is not merely a question of size. Most likely, given the size difference, the small dark cells are unmyelinated and the large light cells are myelinated, although one might expect the cells with the smallest myelinated fibers - the A delta fibers - to belong to the small dark population also. Lawson's data (Lawson, 1979), which suggest that the two populations are already demonstrable in the embryo, might imply that they have a developmental significance, as seems to be the case in the chick (Hamburger et al., 1981). What is still unclear is which physiological functions fall into which histochemical group. The only one of these subpopulations for which there are any extensive physiological data is the $\mathrm{SP}^{+}$population, which seems to be involved in nociception, although the exact role of SP in nociception is controversial (see Wall and Fitzgerald, 1982). The distribution of the $\mathrm{TH}^{+}$cells, being found only in DRG of the lower lumbar region, where they make up $1 \%$ of the total cells (Price and Mudge, 1983), and in the nodose and petrosal ganglia (Katz et al., 1983), suggests that they might be visceral afferents, but their physiological role requires further investigation. 

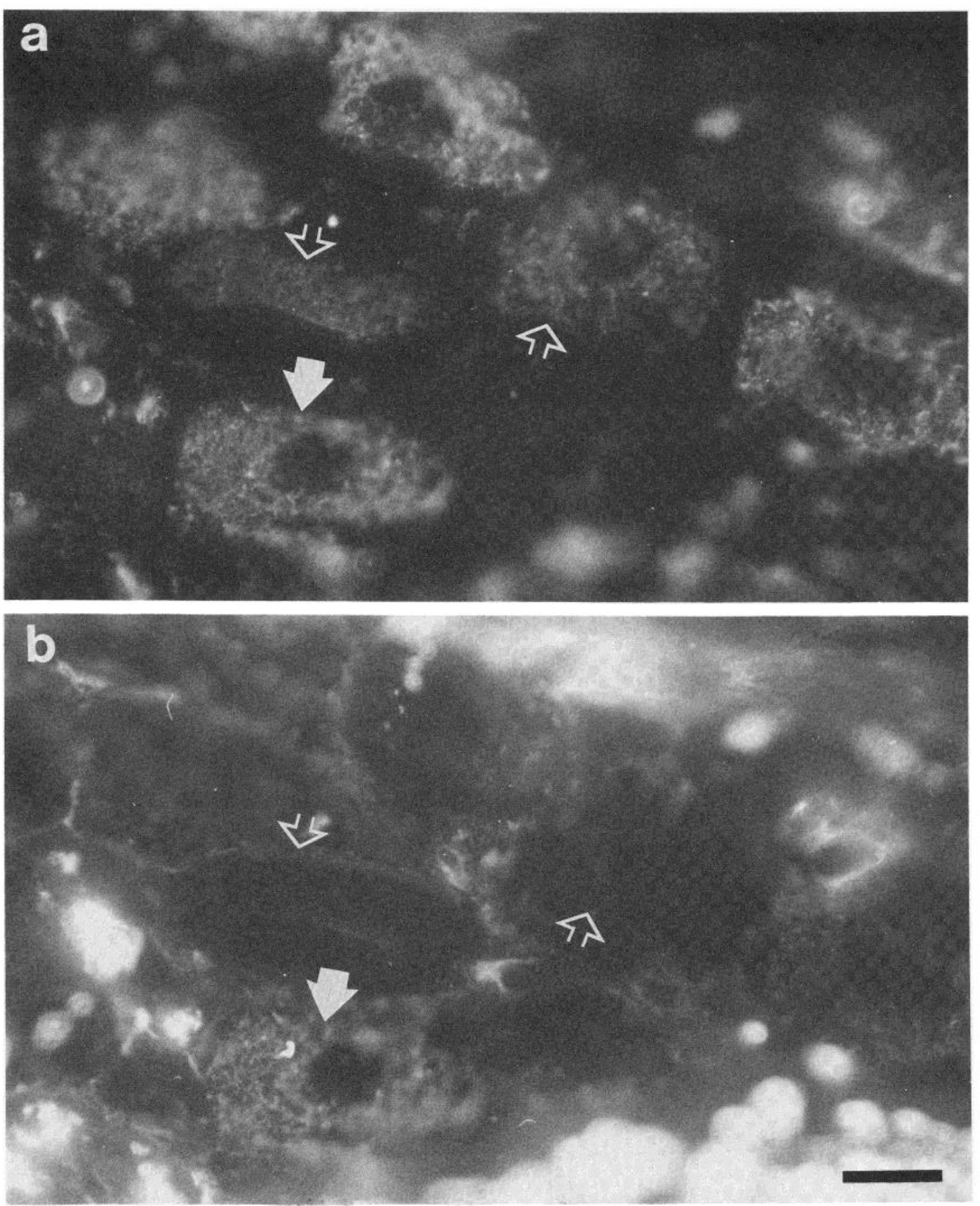

Figure 6. Micrographs showing double-label fluorescent immunohistochemistry. $a$, Anti-68k staining with fluorescein fluorophore. $b$, The same field showing RT97 staining with rhodamine fluorophore. The solid arrow indicates a cell which is stained with both antisera. The open arrows indicate cells which are stained with anti-68k but not with RT97. Scale bar, $20 \mu \mathrm{m}$.

As previously mentioned, Anderton et al. (1982) have claimed that RT97 is a marker of "large light" sensory neurons. This was argued from the observation that the size distribution of $\mathrm{NF}^{+}$cells fitted that of the large light subpopulation. However, this is not a particularly stringent test as the large light cells cover such a broad size range. Also, the present study has shown that there are RT97- cells so large that they could hardly be considered "small dark" cells. Nonetheless, the fact that the four putative small dark subpopulations fail to stain with anti-neurofilament supports both the proposition that they are indeed small dark cells and that RT97 marks the majority of neurons belonging to the large light group.

The distribution of different types of neurons in sensory ganglia is of interest for at least two different reasons. First, if different neuronal types had unequal distributions within a ganglion, then this might explain some of the variation between different estimates of the proportion of sensory neurons that are of a particular type. Such variation can be found in the literature where the number of $\mathrm{SP}^{+}$ cells, for example, has been estimated at between 10 and $20 \%$ (Hokfelt et al., 1976; Dalsgaard et al., 1982; Panula et al., 1983). The second point is that such a distribution might have some physiological or developmental significance.

The results with SP and SOM give no indication of a systematic organization of sensory neurons and indicate no basis for the observed variation. The FRAP results are more difficult to interpret. 
The findings using $10-\mu \mathrm{m}$ sections seem clear. They strongly sug gest that FRAP ${ }^{+}$cells are found predominantly in the dorsal half of the $L 6$ ganglion and that this result was consistently true from animal to animal and for both left and right ganglia. It is also difficult to see what artifact could generate this result, as the staining of all sections was done simultaneously and a ganglion could be cut such that one section had both FRAP-rich and FRAP-poor areas (see Fig. 4). Also, no colchicine was involved in these experiments.

This makes the discrepancy generated by the $20-\mu \mathrm{m}$ sections all the more surprising. Clearly, many FRAP ${ }^{-}$cells became FRAP $^{+}$ when stained in thicker sections, but the reason for this remains obscure. I have found the FRAP technique to be fairly capricious; it has worked and failed using a number of fixation protocols and section thicknesses (data not shown). However, these further experiments have provided no insight into why there should be conditions under which cells on the ventral half of the ganglion do not stain while others on the dorsal half do. Nonetheless, whatever the basis of this discrepancy, these results reveal a possible heterogeneity between dorsal and ventral DRG neurons in the amount of FRAP or its properties in the cells. It also points out some of the potential pitfalls of comparing results from different experiments where variations of this technique have been used.

\section{References}

Anderton, B., H. B. Coakham, J. A. Garson, A. A. Harper, and S. N. Lawson (1982) A monoclonal antibody against neurofilament protein specifically labels the large light cell population in rat dorsal root ganglia. J. Physiol. (Lond.) 334: 97-98P.

Andres, K. H. (1961) Untersuchung uber den Feinbau von Spinalganglien. Z. Zellforsch. mikrosk. Anat. 55: 1-48.

Barber, R. P., J. E. Vaughn, J. R. Slemmon, P. M. Salvaterra, E. Roberts, and S. E. Leeman. (1979) The origin, distribution and synaptic relationships of substance P axons in rat spinal cord. J. Comp. Neurol. 184: 331-351.

Dalsgaard, C. J., S. R. Vincent, T. Hokfelt, J. M. Lundberg, A. Dahlstrom, M. Schultzberg, G. J. Dockray, and A. C. Cuello (1982) Coexistence of Cholecystokinin- and Substance $\mathrm{P}$-like peptides in neurons of the dorsal root ganglia of the rat. Neurosci. Lett. 33: 159-163.

Duce, I. R., and P. Keen (1977) An ultrastructural classification of the neuronal cell bodies of the rat dorsal root ganglion using zinc iodide-osmium impregnation. Cell Tissue Res. 185: 263-277.

Hamburger, V., J. K. Brunso-Bechtold, and J. W. Yip (1981) Neuronal death in the spinal ganglia of the chick embryo and its reduction by nerve growth factor. J. Neurosci. 1 : 60-71.

Hatai, S. (1902) Number and size of the spinal ganglion cells and dorsal root fibres in the white rat at different ages. J. Comp. Neurol. 12: 107-124.

Hokfelt, T., J. -O. Kellerth, G. Nilsson, and B. Pernow (1975a) Substance P: Localisation in the central nervous system and in some primary sensory neurons. Science 190: 889-890.

Hokfelt, T., J. O. Kellerth, G. Nilsson, and B. Pernow (1975b) Experimental immunohistochemical studies on the localisation and distribution of substance $\mathrm{P}$ in cat primary sensory nourons. Brain Res. 100: 235252.

Hokfelt, T., R. Elde, O. Johansson, R. Luft, and A. Arimura (1975c) Immunohistochemical evidence of the presence of somatostatin, a powerful inhibitory peptide, in some primary sensory neurons. Neurosci. Lett. 1 : 231-235.

Hokfelt, T., R. Elde, O. Johansson, R. Luft, G. Nilsson, and A. Arimura (1976) Immunohistochemical evidence for separate populations of somatostatincontaining and substance P-containing primary afferent neurons in the rat. Neuroscience 1: 131-136.

Jacobs, J. M., N. Carmichael, and J. B. Cavanagh (1975) Ultrastructural changes in the dorsal root and trigeminal ganglia of rats poisoned with methyl mercury. Neuropathol. Appl. Neurol. 1: 1-19.

Joh, T. H., C. Gcghman, and D. Reis (1973) Immunochemical demonstration of increased accumulation of tyrosine hydroxylase protein in sympathetic ganglia and adrenal medulla elicited by reserpine. Proc. Natl. Acad. Sci. U. S. A. 70: 2767-2771.

Katz, D. M., K. A. Markey, M. Goldstein, and I. B. Black (1983) Expression of catecholaminergic characteristics by primary sensory neurons in the normal adult rat in vivo. Proc. Natl. Acad. Sci. U. S. A. 80: 3526-3530.

Knyihar, E. (1971) Fluoride-resistant acid phosphatase system of nociceptive dorsal root afferents. Experientia 27: 1205-1207.

Lawson, S. N., K. W. T. Caddy, and T. J. Biscoe (1974) Development of rat dorsal root ganglion neurons. Cell Tissue Res. 153: 399-414.

Lawson, S. N. (1979) The postnatal development of large light and small dark neurons in mouse dorsal root ganglia: A statistical analysis of cell numbers and size. J. Neurocytol. 8: 275-294.

Lieberman, A. R. (1976) Sensory ganglia. In The Peripheral Nerve, D. N. Landon, ed., pp. 188-278, Chapman and Hall, London.

Nagy, J. I., and S. P. Hunt (1982) Fluoride-resistant acid phosphatasecontaining neurons in dorsal root ganglia are separate from those containing substance $P$ or somatostatin. Neuroscience 7: 89-97.

Panula, P., M. Hadjiconstantinou, H. -Y. T. Yang, and E. Costa (1983) Immunohistochemical localization of bombesin/gastrin-releasing peptide and substance $P$ in primary sensory neurons. J. Neurosci. 3: 2021-2029.

Preto Parvis, V. (1954) Distribution of two types of nerve cells with different evolution characteristics in the spinal ganglia of the cat. Monit. Zool. Ilal. 63. suppl. 352-354.

Price, J. (1984) Immunohistochemical evidence for dopaminergic neurones in the rat superior cervical ganglion. Proc. Roy. Soc. Lond. B. 222: 357362.

Price, J., and A. W. Mudge (1983) A subpopulation of rat dorsal root ganglion neurones is catecholaminergic. Nature 301: 241-243.

Rambourg, A., Y. Clermont, and A. Beaudet (1983) Ultrastructural features of six types of neurones in rat dorsal root ganglia. J. Neurocytol. 12: 4766.

Scharf, J. H. (1958) Sensible ganglien. In Handbuch der mikroscopischen Anatomie des Menschen. Zweiter Band, dritten Teil, W. von Mollendorf and W. Bargmann, eds., pp. 135-352, Springer-Verlag, Berlin.

Sharp, G. A., G. Shaw, and K. Weber (1982) Immunoelectron microscopical localisation of the three neurofilament triplet proteins along neurofilaments of cultured dorsal root ganglion neurones. Exp. Cell Res. 137: 403-413.

Shaw, G., and K. Weber (1981) The distribution of the neurofilament triplet proteins within individual neurones. Exp. Cell Res. 136: 119-125.

Sternberger, L. A., and S. A. Joseph (1979) The inlabeled antibody method. Contrasting colour staining of paired pituitary hormones without antibody removal. J. Histochem. Cytochem. 27: 1424-1429.

Wall, P. D., and M. Fitzgerald (1982) If substance $P$ fails to fulfill the criteria as a neurotransmitter in somatosensory afferents, what might be its function? Ciba Found. Symp. 91: 249-266.

Wood, J. N., and B. H. Anderton (1981) Monoclonal antibodies to mammalian neurofilaments. Biosci. Rep. 1: 263-268. 